\title{
A Linguistic View of a Twitter Apology
}

\author{
Mackenzie Croley ${ }^{1}$
}

${ }^{1}$ Xavier University, New Orleans, LA, USA

\section{ABSTRACT}

This study examines a Twitter apology posted by Bella Thorne after an OnlyFans scandal of August 2020. This study broke down the language used in multiple tweets to examine the types of phrases being used, the connotation of the words used, and its overall success in serving as an apology. While the apology tweeted by Thorne has some qualities of a standard apology, the order of these conventions did not serve her apology well. Thorne also fails to show that she understands the online sex work community and reinforces a stigma of online sex work both in her actions and in the words of her apology. This study briefly highlights the importance of move structures for its successful in its genre, especially online.

\section{Introduction}

Sex work has existed for centuries. With the rise of technology, sex work has, in a large degree, moved into digital formats. This includes a range from pornography to escort sites to sex hot lines. One website with increasing popularity is OnlyFans. This is a site for any content creator to share their exclusive content to their paying fans (OnlyFans 2020). While this is not exclusively a website for pornographic material, many content creators and fans use it for that purpose as it creates a more intimate connection from creator to customer. There was a spike in use of the website during the world-wide lockdowns due to COVID-19. Many joined as content-creators during an economic crisis and others, customers and creators alike, joined because they were quarantined at home for months. This also drew in celebrities, particularly Bella Thorne, a former child Disney star. After this actress joined the site, she raked in over 2 million dollars in under a week, a record-breaking amount for the site. Her addition to the site led to a scam she pulled over many OnlyFans customers, resulting in record amounts of refunds. Thorne promised a nude photo to customers who paid 200 USD in a pay-per-view like feature on the site. However, the image showed Thorne in a lingerie set, not nude. As this is not the content users paid for, they had the opportunity to ask for a refund. OnlyFans refunded thousands of users and, shortly thereafter, the site changed their policy about the amount content creators could charge for their content; this directly impacted smaller creators who received large pay cuts. Many content creators, such as Erika Heidewald, brought attention to this situation via Twitter. Thorne shortly issued an apology many content creators found inadequate. The fight to pay sex workers fairly and safely is a difficult and long process and one that many fight for daily. Occurrences like this and the lack of accountability often do more harm than intended.

The text in consideration is a twitter apology tweeted by Bella Thorne after she received mass amounts of backlash for her actions on OnlyFans. Apologies tend to follow an unspoken pattern. The closer this pattern is followed, the more successful the apology. This social routine is learned by people in observing others give apologies and the success of their own apology. Taking responsibility, being sincere, and making amends are all some of the important aspects in creating a successful apology. Another aspect to the success of the apology is the words chosen by the author of the apology. A big question presented when reading an apology is the genuineness of the apologizer. The words chosen often reveal whether the apology is genuine or not. Many words choices can make an apology fall short. Through a linguistic analysis, I provided evidence that Thorne's twitter apology was overall unsuccessful by analyzing the words she chose through the lenses of connotation and speech acts. 


\section{Literature Review}

Bella Thorne's apology for her actions on her OnlyFans platform joined a new but growing genre of Twitter apologies. Twitter is a social media platform where any user can create posts, or tweets, of 280 characters. ${ }^{i}$ If the user is not able to fit their entire tweet into 280 characters, a common practice is replying to their own tweet, creating a twitter thread. While celebrities make Twitter apologies occasionally, it is not the most popular platform or mode to make apologies. Many celebrities have used videos posted to Youtube as a form of apologizing for their actions. ${ }^{\text {ii }}$ Most significant twitter apologies come from companies who have made smaller mistakes, such as unclean stores and product issues. While companies and celebrities may share different practices in apologies, the most important part of their apology (genuine or un-genuine regrets aside) is to keep the brand name intact. Celebrities have become brands of their own. Many people will see a movie with a favorite actress or go to a festival with a favorite singer. Alternatively, people may refuse such media because of a celebrity. Boycotting celebrities or companies due to their actions, recently referred to as "cancel culture" (Greenspan 2020), can be harmful to income and image of celebrities and companies. Apologies, whether issued via tweet, video, or another media form, has become necessary when a mistake has been made.

In a study by Ruth Page (2013), the use of the speech acts as apologies used by corporate companies via Twitter was dissected. Most of the Twitter apologies fell in at least one of the apology framework categories, if not more. These categories consist of Illocutionary Force Indicating Device, ${ }^{\text {iii }}$ Taking Responsibility, Explanation or Account, Offer of Repair, and Promise of Forbearance which were established by Blum-Kulka et al. (Page 2014, 32). By using these frameworks in an apology, it often helps the company apologies better repair their image. Hundreds of tweets were studied in comparison with each other. An early consensus of the study was that apologies were necessary to keep the company from further image damage. Depending on the complaint, the company attempted to make amends in the most fitting way so that that particular customer was no longer upset and other customers did not find offense in addition to the original complaint and therefore be deterred from using the company product. Another interesting note in the study was that companies who had a stake in the repair of their brand name, often promised to further investigate the issue. This is important to note as it shows that the company is honestly invested in the customer and those it may have harmed.

As the OnlyFans page has only been a company for about 4 years (OnlyFans 2020) and only recently grew in popularity, there has been little to no academic research done on the site.

My research question is examining the text for the effectiveness of the twitter apology from a linguistics perspective. I am curious about how words can have many different meanings and the way that they are used in the text can change their meaning. I am also interested in the impact of words as well as how their location within the text affects the impact.

\section{Theory}

In this discourse analysis, iv I used the lenses connotations and speech acts. Tweets, like any text, never stand alone in the world. Those who tweet the text also bring to their keyboard their own motivations whether they are conscious or unconscious. Through this discourse analysis, there was an examination of the Twitter user Bella Thorne. She has her own motivations for the twitter thread she tweeted and by using linguistic tools, it becomes more clear what those motivations may be and their effectiveness in doing so.

\section{Methodology}

The frames used to analyze the text are connotation ${ }^{\mathrm{v}}$ and speech acts. ${ }^{\mathrm{vi}}$ I examine the words used by Thorne and coded the words for possible intention, location within the text, and perceived impact. These categories have been inspired 
by a similar study by Meaghan McHugh which studied tweets associated with cyberbullying (2019, 98-102). Certain relevant words used by Thorne in her twitter thread were selected by my discretion. Then, these words were examined for their denotation provided in the Merriam-Webster Dictionary. Next, they were also considered in the context of the surrounding words, the tweet/twitter thread as a whole, and the situation in which they were tweeted. This was accomplished by looking at the locutionary force, ${ }^{\text {vii }}$ illocutionary force, ${ }^{\text {viii }}$ and perlocutionary force ${ }^{\text {ix }}$ Each word's possible intent, location, and perceived impact were noted. The way the apology was crafted as a whole was also considered through move structures, the typical conventions of a type of text (Jones 2019, 9). After breaking down the language in this matter, each word of the apology was given a code to fit within a category for analysis.

From here, I examined Thorne's status as a celebrity. Thorne is an actress who is dabbling in the sex work industry, does not have any financial need from the industry, and is able to easily find herself in other work. Because of this, many do not see her as a sex worker. Due to this conclusion, Thorne's language about herself versus other content creators was examined. There are many different ways to consider the words she used and how she used them. Some considerations will be: Sex worker vs. Outsider/New Sex Worker/Celebrity; Thorne's concern for the sex work community; structure of an apology; and success of an apology.

\section{Analysis $^{x}$}

While analyzing Thorne's tweets, I considered the many different types of frameworks involved in an apology. I also looked at other parts of speech involved in the tweets so I could determine the speech acts were involved in her apology. I focused not only on the amount of times certain words were used, but also the placement in relation to other parts of the apology.

Before looking directly at the words chosen by Thorne in her apology, the success of the apology is also directly related to the delivery of her apology. Thorne chose to use Twitter as a social media platform to make her apology. Considering her audience is OnlyFans content creators, this was a good decision. Many sex workers involved with OnlyFans, such as Erika Heidewald, had already been using this social media platform to speak out against Bella Thorne and to educate others about the incident. By using twitter to respond, Thorne reached out on the same level as the others. Twitter is also a casual and frequently used social media site. However, the seriousness of the apology could be questioned by using a more casual mode. Although, as this site is frequented by the sex workers and content creators hurt by Thorne's actions, this mode of apology is best.

\section{Subject of the Sentences}

The first piece of the apology I examined was the amount Thorne referred to herself versus the amount she referred to OnlyFans content creators in her five-tweet-long apology. Thorne used the word "I" 12 times in the length of her apology. She only used words like "you" or "content creators" in reference to the OnlyFans content creators a total of 5 times. The placing of these words was not significant in comparison to some of the other findings as it was fairly distributed evenly throughout the tweets. However, there is significance in the imbalance of who was being mentioned. Apologies are typically given to others because of wrong doing by one of the parties. A majority of Thorne's "I" statements are surrounded with words that explain the reason behind the incident or with words that are apologetic. In a more successful apology, the apologizer might only use "I" statements in conjunction with apologetic words and focus more heavily on the harm that has been done to the person or community.

While it understandable why Thorne would use "I" statements in her apology, a question arises surrounding the sheer number of those statements. A portion of these statements make up pieces of standard apologies. There is explanation of intent, apologetic words, and offers to make amends. One thing that is lacking is Thorne's ability to take responsibility for her actions. Throughout her twitter thread, she does not ever reiterate her actions. ${ }^{\mathrm{xi}}$ Page, in her study, notes that reiterating the incident in an apology often caused the negative image of the apologizer to continue 
$(2014,36)$. However, Page's findings referenced more minor issues like product quality $(2014,36)$. Thorne's offense was much more major. Thorne might have benefited in her apology by acknowledging what her actions were. This may have resulted in more "I" statements, but she could have also directed this explanation in a way that shows her understanding of how she directly harmed the OnlyFans content creator community. This would have resulted in more statements about the content creators as well.

Twice in her thread, Thorne uses the phrase "I hurt you" which is the closest Thorne comes to taking responsibility for her actions. By including this phrase in her apology thread, readers do see that Thorne acknowledges that her actions were harmful to the community. However, Thorne does not make it clear how she has harmed the OnlyFans content creators. Without taking responsibility directly for her actions, it does not show her full understanding of the harm she has caused.

\section{Explanation and Justification}

Another large part of Thorne's apology is the types of phrases used to explain her reasons behind the incident. I have divided her explanations into two categories: self-reported intent and justification. Self-reported intent refers to her motivations that she explains behind her actions. Justification refers to the reasons she believed she was qualified and well-versed with sex work to become involved with OnlyFans. She has four statements relating to self-reported intent and four statements relating to justification. While explanations for wrong doings are sometimes necessary, Thorne relies heavily on these sections in her apology. These explanations are a majority of her first four tweets (out of the five tweets within the thread) and all occur before Thorne has issued her first apology. Along with the over-explanation of her reasoning, the placement of these explanations in consideration of the other sections of an apology are not ideal as more successful apologies admit wrong-doing before explaining or justifying the mistake.

There are four instances within the Twitter apology that Thorne uses language to describe her intent. I determined this by looking for words that reflected this like "want" and "try" which were usually following or followed by some kind of intention. Her self-reported intentions were removing the stigma associated with sex work and bringing a public face to the platform. Thorne says, "I was trying...to help bring more faces to the site to create more revenue for content creators on the site" in her first tweet. While Thorne is stating here that her intention was to bring more faces to OnlyFans, it also implies that her face will be able to bring in more revenue because she is better than the sex workers and are more successful than them. The illocutionary force of providing this example and others throughout the tweets is so that the readers understand where Thorne is coming from and why she acted in the way she did. However, looking at the text under the perlocutionary force, Thorne may be seen as arrogant and condescending. She focuses on putting her face on the platform to help de-stigmatize the platform and virtual sex work. This implies that she has a stronger, more influential, and even more important status than the sex workers on this platform.

The way she looks down on sex workers is clear through her vocabulary. Thorne uses the word "help" three times in her stream of tweets. In the Merriam-Webster Dictionary, help is defined as "to give assistance or support" ("help"). Thorne might have been using this word to show her care for the sex worker community. However, it seems the connotation associated with this word in this circumstance has a different effect than her stated intention. The sex work community is sometimes viewed as people who need to be saved from pimps, drugs, or themselves. Thorne speaks to this stigma in her apology, which serves as proof that she is familiar with this stigma. Yet, some sex workers do not find themselves in need saving and are even proud to be apart of the sex work community as seen in Middleweek's article where she collected a wide selection of tweets by sex workers who were reclaiming what it looked like to be a sex worker (2020). It is possible that sex workers could find offense in Thorne offering to help with something she is not involved in at the same level other sex workers are involved. Thorne's choice of using the word "help" in relation to speaking of herself in high standard makes her apology seem less aware of the struggle around the sex work stigma.

Other words Thorne uses while stating her intent are "try" and "want" which is in part how I determined which parts of her apology could be considered stated intent. The word "try" has less of a malicious connotation to it. 
Try, in this case, seems to be Thorne attempting to do something helpful (whether what she did was beneficial or harmful is not important here). This definition aligns closely to the one in the Merriam-Webster dictionary ("try"). On the other hand, the word "want" seems to have a more negative connotation. Want, in this instance, has a little bit of a selfish connotation. Since Thorne mentions her personal life experience along with her statement of being a public figure, it makes the use of the word "want" more selfish, as if she is working off her own personal agenda.

The second part of the explanation Thorne gives is justifications for attempting her actions. The justification Thorne uses is not entirely an excuse that she says makes her actions okay, but instead she justifies her intentions for her actions. Thorne brings up her own personal experience with sex work as well as her celebrity status. Thorne is best known as an actress and is considered fairly successful. Her first big role in 2010, and one that she is best known for, is on the Disney Channel TV show Shake It Up where she portrayed one of the two leads, CeCe. In 2020, she starred in a Netflix Original: The Babysitter 2. Thorne has clear success in her role as an actress. In her Twitter apology, she mentions writing and directing a pornography film which put her career on the line. Although with the amount of success Thorne has had, it doesn't seem likely she would lose her career over directing a pornography film. Even though Thorne was attempting to show her connectedness to sex work industry and the lengths she would take to help it, the way she ties it back to her being a public figure sends the wrong message.

\section{Savior View}

"I am a mainstream face" claims Thorne. This statement puts Thorne above others who are sex workers and creators on OnlyFans because it implies that they are not mainstream faces. While this may not be her intent, the fact that is is paired with her intent to help out sex workers make the statement read in a more negative light. Thorne seems to be taking on a savior view. She also makes the claim she has "risked [her] career" which sounds a little odd considering her wide-spread success. As someone who is associated with child television, this seems more understandable. However, Thorne has not worked in child television in years and does not show any likelihood of returning. In more recent roles, Thorne has portrayed more sexualized characters, which is fairly common with female actresses in their twenties. Thorne's claim to being associated with something like sex work is risking her career seems a bit far fetched. This claim hurts her apology as she is over-exaggerating. Humility often strengthens the apology and neither of these two statements are humble.

This claim also implies that being associated with sex work is risking a career. This simple phrase signifies that all the people involved in sex work have risked or tarnished their career. This seems to furthering the stigma around sex work, not ending it. If sex work is able to risk or even destroy someone's career, then it implies sex work is negative. This obviously is contributing to the stigma about sex work. Thorne is claiming she wants to help end this stigma, but phrases like this are working against her. It shows that Thorne does not actually understand the sex work community. First, her actions harmed the sex work community on OnlyFans and then this statement casts sex work in a negative light. Again, Thorne is weakening her apology as the statement that she is "risk[ing her] career" will not resonate with the audience because of the implications with this statement.

The most important thing to note about the explanations Thorne provides is the placement of these statements in comparison to the other elements of her apology. The first time Thorne uses the word "sorry" is as the last word in her fourth tweet (of five). This is significantly late in the apology to be first using a word directly related to apologizing. All of the explanation Thorne provides is presented before her apology. This order makes it appear Thorne cares more about getting her name cleared than actually apologizing to the community she hurt.

\section{Apology and Apologetic Words}

The next part of Thorne's apology are the words that actually signify the apology itself. I broke this into two categories when coding the tweets: apology words and apologetic words. Apology words are words that are considered apologies like "sorry", "apologize", etc. Apologetic words are words that signify the author is recognizing they know they need 
to apologize. In these tweets, Thorne uses the phrases "I hurt you" and "This is fucked up" that have been placed into the apologetic words category. As stated earlier, Thorne does not have a linguistic strength in her apology words. First, the placement of the apology words are so much later in the apology, it signifies a lack of importance placed on the actual apology. Also, there is also only two instances of apology words throughout the apology. Perhaps, the apology would have been better received if Thorne had used an apology word before her explanation. In the study by Page, many of the examples of successful apologies from corporations included an apologetic word within the first sentence of the apology, not much further down (2014). This could have made Thorne's apology more successful.

One of Thorne's strengths are her use of apologetic words. The placement of these phrases are much more successful and strategic. Her first apologetic phrase comes within her second tweet, as opposed to her apology words which come much later. There is also a humility to her apologetic phrases. "I hurt you" shows that Thorne is recognizing the harm caused by her actions. As stated earlier, humility is helpful in the success of an apology. This seems to be one of the few times Thorne's illocutionary force aligns with the perlocutionary force. Her phrase "This is fucked up" also shows that Thorne recognizes the gravity of the situation.

Both of these phrases are confessional in tone, especially the phrase "I hurt you." This phrase is recognizing the pain that Thorne has caused. It also is admitting wrong doing which is where the confessional tone comes into play. Part of an apology is admitting wrong doing. By including these confessional-like phrases, it strengthens Thorne's apology. Like it was stated earlier, the apologetic words Thorne uses in her apology are her strongest point of her apology. Thorne also chose to say "This is fucked up" instead of other phrases like "This is messed up" or "This is screwed up" or any other words with similar meaning. Incorporating a swear word in her apology brings a much stronger impact to her words. Swear words are often used to emphasize the words around them. Using such strong language again emphasizes that Thorne understands how badly her actions hurt the sex work community involved with OnlyFans.

\section{Amends}

The final part of Thorne's apology is her attempt to make amends. This is a common part of an apology as it often shows those reciting the apology that they care enough to take the time to make amends for their actions. This shows they actually have that desire and care for the community to make an attempt to reverse the harm they have caused. Thorne places this all in her final tweet. Amends are usually placed at the end of the apology as they consist of the promise of future actions instead of past actions. This is chronologically correct which is why many place their amends at the end of the apology.

The amends Thorne promises to make are to meet with the company OnlyFans to find out why they changed their policy, ask the sex workers and content creators from OnlyFans for their input of what she should bring up to OnlyFans, and to promote other sex workers on her own Twitter. While these amends seem helpful, Thorne again presents the idea that she is superior to the other content creators on OnlyFans. First, by asking other creators to send her their concerns about the OnlyFans policy change. Thorne is making herself the spokesperson for that entire community. She also again highlights that she has a platform which she can promote others' work. This again implies she is in a better position than the other content creators.

There is also the likelihood of Thorne following through with the amends. Her last two amends seem near impossible to fulfill. Both amends are promising to help the sex workers and content creators on OnlyFans by working with them. However, the sheer amount of sex workers and content creators on OnlyFans makes this task impossible. Thorne could not possibly talk to every person who wants to bring a concern to OnlyFans. She can not also possibly promote every single person who asked for her to retweet their work. In fact, many replied to Thorne's tweet with their OnlyFans and content and while other users could see their content from her tweet, Thorne never retweeted or drew any attention or promotion to any of the other sex workers and content creators (as of November 2020 when the analysis was completed). 
Thorne's apology is overall unsuccessful. Many of the words she chooses show her lack of understanding for the sex work and the content creators of OnlyFans community. The impact of her words was mostly negative through her explanation, apology words, and amends. She does have a redeeming apologetic words section making her apology partially effective. Thorne could have made some stronger linguistic choices to strengthen her apology and show her care for the sex workers and content creators of OnlyFans.

\section{Discussion}

Thorne's actions were harmful to the content creators on OnlyFans which prompted her twitter apology. Many content creators were upset by her addition to the site after she scammed thousands of users. One of the biggest concerns presented by Erika Heidewald was the damage Thorne caused to the image of sex workers on OnlyFans. Heidewald explained in her own Twitter thread that Thorne scamming thousands of users added to the narrative that online sex workers are scammers. Thorne, in her own apology, stated that she wanted to help end the stigmas around the sex work industry, but her words prove otherwise. Thorne's apology was not typical of a socially-accepted apology. She explained herself for a majority of the apology and before she had actually said the words "I'm sorry". Thorne focused more on herself than the community she hurt. She also showed a lack of understanding for the harm she had done to the community by some of the statements she had made. Typically, the apologizer should explain that they understand the harm they have caused so that the community can accept that apology. Without a real understanding of the harm caused, the apologizer cannot be truly sorry if they do not understand the entirety of the harm from their actions. If the community does not feel understood, they may reject the apology, which is what occurred in the Thorne's case.

Twitter apologies are a newer phenomenon and there is very limited studies on them. This means that crafting a Twitter apology does not have clear instructions or have conventionalized structures. Standard apologies do have their own structures, but Twitter apologies have their own limitations. For example a character count is in place, which limits how much can be typed in one tweet. Twitter apologies are typed and not spoken, so it is hard to gauge the author's emotions, seriousness, and genuineness. Twitter does allow others to directly comment and respond to the apology so feedback is immediate both for the apologizer and other viewers. Twitter apologies are a growing mode of apologies and slowly conventions are being created. Thorne's Twitter thread can be analyzed as a part of a larger scale study as an unsuccessful apology alongside more successful tweeted apology so that discourse can be better understood and the conventions can be more clearly laid out.

Should Thorne have used a different mode to give her apology? Maybe it would have helped, but maybe it would have hurt. However, Thorne could have chosen her words better. She could have also listened to the sex workers who were affected. There are others that use OnlyFans regularly for income and understand what the community needs better than Thorne. Perhaps if she took another moment to learn from the community about her actions, her apology would have had been more educated about the online sex work community. This would have resulted in a better and more genuine apology. Thorne could have also considered how others have apologized on Twitter and the feedback they have received. If she had followed a more typical apology layout for a standard apology and had made small adjustments to make it suitable for Twitter, she perhaps could have apologized in a more successful way,

\section{Conclusion}

While analyzing the Twitter apology by Thorne under the lenses of connotation and speech acts, I came to understand that Thorne's chosen words were not successful in her apology. While Thorne includes three standard sections of an apology, explanations, apology words, and amends, Thorne's word choice, justifications, and placement of her apology were ultimately more detrimental to the apology than helpful. Her apology failed to properly make up for her actions and possibly made it worse. 
The stigma around sex work, especially online sex work, is very present and causes society to have a negative view of those involved. Communities like this are marginalized because of this stigma. Receiving a giant pay cut from OnlyFans is only a few of their daily struggles. Sex workers are constantly fighting to have their work viewed as a real job. The OnlyFans platform has allowed the sex workers to prove their work is valid. However, any negative backlash on this community forces any progress take giant steps back. The sex workers online are the ones who should be deciding how to help their community better. When outsiders try to help, it can often be hurtful, like it was here, both in actions and in apology. Even with Thorne's apology, many outside of the online sex work community sided with Thorne as they do not understand the community either.

Further studies would be helpful in determining how those outside of sex work discuss the sex work community and whether or not it is successful. While Thorne stated her intentions were to help, her words were harmful. They showed she did not completely understand the community she was trying to help and she also furthered the sex work stigma. Other researchers could look at other celebrities who want to help end the stigma around sex work and consider the texts they use to talk about sex workers. Thorne, while trying to help, showed those who care about the sex work community that there is still a long ways to go in understanding and de-stigmatizing their community.

My analysis demonstrates how linguistic analysis can help us come to solid conclusions about how others speak and what impact it has on many communities. With these findings, we can recognize ways to avoid harmful language and instead use language that is beneficial to all communities and start breaking down the stigmas that surround them. In particular, there are many ways to help end the stigma around sex workers and their industry. Through fully understanding the impact our words have, we can be the change necessary.

\section{Bibliography}

Allan, Kieth. 2006. “The Pragmatics of Connotation.” In Journal of Pragmatics 39: 1047-1057.

Anand, Tara. 2018. "A Brief Summary of the Third Wave of Feminism.” Feminism in India, April 27, 2018. https://feminisminindia.com/2018/04/27/brief-summary-third-wave-of-feminism/

Berry, Allen. 2018. "A One-Hundred Forty Character Discourse: The Twitter Apology as an Emerging Sub-Genre of Corporate Communication.” In Technical Communication 65, no. 1: 9-30.

Carman, Ashley. 2020. "OnlyFans Confirms New Caps on Tips and Pay-Per-View Content, but Says the Changes are Unrelated to Bella Thorne." The Verge, September 1, 2020. https://www.theverge.com/2020/9/1/21405540/onlyfans-rule-change-tips-pay-update-bella-thorne

Greenspan, Rachel. "How 'Cancel Culture' Quickly Became One of the Buzziest and Most Controversial Ideas on the Internet." Insider, August 6, 2020. https://www.insider.com/cancel-culture-meaning-history-origin-phrase-usednegatively-2020-7

Heidewalk, Erika (@erikaheidewald).2020. “And while you're here, SUPPORT SEX WORKERS. If you watch porn, make it ethical porn that the creators get paid for. Free porn is usually just stolen content posted without consent. Don't support that just bc it's free. Entertainers deserve to be paid for our work." Twitter, Aug 28, 2020. https://twitter.com/erikaheidewald/status/1299477241705803776

Heidewalk, Erika (@erikaheidewald). 2020. “Bella Thorne is one of these people. Bella Thorne does not care if sex workers can make money, if they can survive, if they can get respect for their work. She thought it would be fun to wade into our life carelessly and in doing hurt our ability to provide for ourselves." Twitter, Aug 28, 2020.

https://twitter.com/erikaheidewald/status/1299472697827536897 
Heidewalk, Erika (@erikaheidewald). 2020. “If you don’t understand why every sex worker hates Bella Thorne’s stinky guts and how she endangered the livelihood of hundreds of thousands of creators, let me explain it for you! First, Bella Thorne made an OF \& made \$1m in her first day. This isn't the bad part.” Twitter, Aug 28, 2020. https://twitter.com/erikaheidewald/status/1299467098100396032

Heidewalk, Erika (@erikaheidewald). 2020. "Is it worth it to you to sell videos of yourself sucking dick for a maximum of $\$ 32$ ? Can you make a living at it? What if you used to sell them for $\$ 150$ or $\$ 200$, can you survive a paycut like that? Could YOU at YOUR job survive a sudden 85\% paycut \& monthly payday?” Twitter, Aug 28, 2020. https://twitter.com/erikaheidewald/status/1299471249173749760

Heidewalk, Erika (@erikaheidewald). 2020. “Now about the \$50 PPV and \$100 tip cap. I’ve seen people who are not sex workers saying this seems "reasonable" bc you are ignorant morons talking on something you don't understand. Sex workers don't get paid hourly. You make larger amounts inconsistently.” Twitter, Aug 28, 2020. https://twitter.com/erikaheidewald/status/1299469927934435328

Heidewalk, Erika (@erikaheidewald).2020. "Now a lot of people fundamentally do not care about this predicament bc you don't care about the lives and livelihoods of sex workers. And yet you still want to see porn, you just don't believe the people who create it deserve to survive. You're a bad person and fuck you." Twitter, Aug 28, 2020. https://twitter.com/erikaheidewald/status/1299472289977700352

Heidewalk, Erika (@erikaheidewald). 2020. “People can make different kinds of content as sex workers. I make a lot less explicit content than some of my friends just bc I have my own comfort level I stick to. I don't care if people make OnlyFans and post lingerie pics only. But you don't scam \& you don't feel superior.” Twitter, Aug 28, 2020. https://twitter.com/erikaheidewald/status/1299473862577455104

Heidewalk, Erika (@erikaheidewald). 2020. “People have bills to pay. Kids to feed. Many people, including content creators and sex workers, live paycheck to paycheck. How are they going to pay their bills this month? How are they going to feed themselves and their families? This is REAL HARM.” Twitter, Aug 28, 2020.

https://twitter.com/erikaheidewald/status/1299469499121377280

Heidewalk, Erika (@erikaheidewald).2020. “PPV messages are frequently used by sex workers to sell more explicit content. Let's say you're selling a video of you sucking your boyfriend's dick. If you sell that for $\$ 50$, OF keeps $20 \%$, so you get $\$ 40$. BUT you have to pay taxes on that. Maybe you get $\$ 30-32$.” Twitter, Aug 28, 2020. https://twitter.com/erikaheidewald/status/1299470711887544320

Heidewalk, Erika (@erikaheidewald). 2020. "Previously, the funds you made on OF were only pending for a week, so most creators got paid at least once a week. Imagine suddenly going from a weekly paycheck to a monthly paycheck. That's what's happening to 450,000 content creators." Twitter, Aug 28, 2020. https://twitter.com/erikaheidewald/status/1299469023453745153

Heidewalk, Erika (@erikaheidewald). 2020. “She didn’t think about us as real people or about sex work as a real job. She SCAMMED people, which leads to the spread of a dangerous and unfair stereotype that sex workers are scammers even though every content creator I know works their ass off \& cares about providing value." Twitter, Aug 28, 2020. https://twitter.com/erikaheidewald/status/1299473155082186753

Heidewalk, Erika (@erikaheidewald). 2020. “So suddenly a fuck ton of people ask for a charge back and this causes problems for OnlyFans bc they have processing costs, so people suddenly requesting millions in chargebacks makes them lose a lot of money." Twitter, Aug 28, 2020. https://twitter.com/erikaheidewald/status/1299468141580283904 
Heidewalk, Erika (@erikaheidewald). 2020. “Then, she sent out a \$200 PPV message that she claimed was a nude photo but when subscribers paid to open it, they found it was a lingerie photo. Seeing as she SCAMMED them, they wanted their money back and OF has a policy that you get your money back if you get scammed." Twitter, Aug 28, 2020. https://twitter.com/erikaheidewald/status/1299467614909902849

Heidewalk, Erika (@erikaheidewald). 2020. “There has been a huge backlash and OF might be backtracking on some of these policies. It's hard to know bc they frequently dismiss sex workers 'concerns and many SWers already have a hard time getting their money from OF. But the outrage might help so join us \& get pissed off." Twitter, Aug 28, 2020. https://twitter.com/erikaheidewald/status/1299476697712963584

Heidewalk, Erika (@erikaheidewald).2020. “To be able to pay all those people back and prevent such a massive chargeback problem in the future, OnlyFans changes their policies so now the maximum price for a PPV message is $\$ 50$, maximum tip someone can send is $\$ 100$, and all the money you make on OF is pending for 30 days." Twitter, Aug 28, 2020. https://twitter.com/erikaheidewald/status/1299468525287821314

Jones, Rodney H. 2019. Discourse Analysis. 2nd ed. New York, NY: Routledge.

Lin, Ying. 2020. "10 Twitter Statistics Every Marketer Should Know in 2020 (Infographic).” Oberlo, May 30, 2020. https://www.oberlo.com/blog/twitter-statistics

McHugh, Meaghan, Sandra Saperstein, and Robert Gold. 2019. "OMG U \#Cyberbully! An Exploration of Public Discourse About Cyberbullying on Twitter." In Health Education \& Behavior 46, no. 1: 97-105.

Merriam-Webster, "help". In Merriam Webster Dictionary. https://www.merriam-webster.com/dictionary/help

Merriam-Webster, “try”. In Merriam Webster Dictionary. https://www.merriam-webster.com/dictionary/try

Middleweek, Belinda. 2020. "Pussy Power Not Pity Porn: Embodied Protest in the \#FacesOfProstitution Twitter Network.” In Sexualities 23, no. 3: 342-360.

OnlyFans, 2020. "How to Use: OnlyFans.” OnlyFans. https://onlyfans.com/how

Page, Ruth. 2014. “Saying 'Sorry’: Corporate Apologies Poster on Twitter.” In Journal of Pragmatics 62: 30-45.

Thorne, Bella (@bellathorne). 2020. “behind anything sex related. I wrote and directed a porn against the high brows of my peers and managers because I WANTED to help with the stigma behind sex.” Twitter, Aug 29, 2020. https://twitter.com/bellathorne/status/1299835831419416577

Thorne, Bella (@bellathorne).2020. “...I am a mainstream face and when you have a voice, a platform, you try to use you in helping others and advocate for something bigger than yourself. Again in this process I hurt you and for that I'm truly sorry." Twitter, Aug 29, 2020. https://twitter.com/bellathorne/status/1299836063217721345

Thorne, Bella (@bellathorne).2020. “I wanted to bring attention to the site, the more people on the site the more likely of a chance to normalize the stigmas, And in trying to do this I hurt you. I have risked my career a few times to remove the stigma behind sex work, porn, and the natural hatred people spew...” Twitter, Aug 29, 2020.

https://twitter.com/bellathorne/status/1299835673541656576 
Thorne, Bella (@bellathorne). 2020. “Ps. I’m meeting with only fans about the new restrictions to find out why!!! This is fucked up and I'm sorry comment any ideas or concerns you want brought up to OF!! and send me your links and a pic so I can promote you guys" Twitter, Aug 29, 2020. https://twitter.com/bellathorne/sta$\underline{\text { tus } / 1299836417154015232}$

Thorne, Bella (@bellathorne). 2020. "PT1 Remove the stigma behind sex, sex work, and the negativity that surrounds the word SEX itself by bringing a mainstream face to it that's what I was trying to do, to help bring more faces to the site to create more revenue for content creators on the site." Twitter, Aug 29, 2020. https://twitter.com/bellathorne/status/1299835299132891136

Twitter. 2020. “About Twitter.” Twitter. https://about.twitter.com 